\title{
A Unique Esophageal Motor Pattern That Involves Longitudinal Muscles is Responsible for Emptying in Achalasia Esophagus
}

\author{
Su Jin Hong, MD PhD*, Valmik Bhargava, PhD, Yanfen Jiang, MD, Debbie DenBoer, RN, and \\ Ravinder K. Mittal, MD \\ he Division of Gastroenterology, San Diego VA Health Care System; University of California, San \\ Diego, CA, USA \\ "Department of Internal Medicine, Soonchunhyang University School of Medicine, Bucheon, South \\ Korea
}

\begin{abstract}
Background \& Aims-Achalasia esophagus is characterized by loss of peristalsis and incomplete esophago-gastric junction (EGJ) relaxation. We studied mechanisms of esophageal emptying in patients with achalasia using simultaneous high-resolution manometery (HRM), multiple intraluminal impedance (MII), and high frequency intra-luminal ultrasound (HFIUS) image recordings.
\end{abstract}

Methods-Achalasia was categorized into 3 subtypes, based on the esophageal response to swallows: types 1 and 2 were defined by simultaneous pressure waves of $<30 \mathrm{mmHg}$ and $>30$ $\mathrm{mmHg}$, respectively, and type 3 was defined by spastic simultaneous esophageal contractions.

Results-Based on HRM, a predominant achalasia pattern of type 2 was characterized by a unique motor pattern that consisted of upper esophageal sphincter contraction, simultaneous esophageal pressure (panesophageal pressurization), and EGJ contraction, following swallows. HFIUS identified longitudinal muscle contraction of the distal esophagus as the cause of panesophageal pressurization in type 2 achalasia. MII revealed that esophageal emptying occurred intermittently (36\% swallows) during periods of panesophageal pressurization. Patients with achalasia of types 1 and 3 had no emptying or relatively normal emptying during most swallows, respectively.

Conclusion-In achalasia, esophageal emptying results from swallow-induced longitudinal muscle contraction of the distal esophagus; which increases esophageal pressure and allows flow across the non relaxed EGJ to take place

\section{Keywords}

Esophageal Longitudinal Muscle Contraction; Lower Esophageal Sphincter; Esophago Gastric Junction Achalasia; Ultrasound Imaging Esophagus

(C) 2010 The American Gastroenterological Association. Published by Elsevier Inc. All rights reserved.

Address Correspondence to: Dr. R.K. Mittal, Gastroenterology (111D), San Diego VA Health Care System 3350 La Jolla Village Drive, San Diego, CA 92161.rmittal@ucsd.edu.

Author contributions: SJ Hong acquired and analyzed the data wrote the manuscript; V Bhargava, and RK Mittal designed the experiment; V Bhargava also developed the software for data analysis created the figures; Mittal and Bhargava are PI and Co-PI of the $\mathrm{NIH}$ grant, they helped with manuscript editing; Y Jiang helped with data analysis; D DenBoer recruited the subjects, helped with the procedures and data acquisition.

Publisher's Disclaimer: This is a PDF file of an unedited manuscript that has been accepted for publication. As a service to our customers we are providing this early version of the manuscript. The manuscript will undergo copyediting, typesetting, and review of the resulting proof before it is published in its final citable form. Please note that during the production process errors may be discovered which could affect the content, and all legal disclaimers that apply to the journal pertain.

Conflict of Interest: There is no conflict of interest in this study. 


\section{INTRODUCTION}

Achalasia esophagus, a major motility disorder results from degeneration of the myenteric plexus in the wall of the esophagus and the lower esophageal sphincter (LES)1. Immunohistochemical staining studies show that there is selective loss of nitric oxide synthase (NOS) from the neurons of myenteric plexus of the LES in achalasia esophagus2, 3. Manometrically, impaired relaxation of LES and loss of peristalsis in the body of the esophagus are the hallmark of achalasia esophagus. Recent studies show that there is considerable heterogeneity in the disease severity, radiologic, manometric and histologic findings in patients with achalasia esophagus2. Based on the high resolution manometry (HRM) recordings, Pandolfino et al proposed a new classification scheme of achalasia esophagus that has important prognostic implications, i.e., it may determine the treatment outcome 4.

Patients with achalasia esophagus present with moderate to severe dysphagia, chest pain and heartburn symptoms ${ }^{5-7}$. Dysphagia in achalasia is to both, solids and liquids and can result in significant weight loss over short period of time. The mechanism of dysphagia in achalasia is related to poor esophageal emptying which in turn is related to impaired LES relaxation and lack of esophageal peristalsis. Radiologic and radionuclide esophageal emptying studies show that the esophageal emptying in achalasia is incomplete ${ }^{8,} 9$. Even though incomplete, esophageal emptying does take place intermittently in achalasia. It is generally assumed that in the absence of peristalsis and incomplete LES relaxation, esophageal emptying in achalasia is likely related to gravity because patients generally eat in the upright posture. Some achalasia patients assume different postures and perform various maneuvers to increase intra-thoracic pressure that facilitates esophageal emptying. However, to the best of our knowledge the precise mechanism by which esophageal emptying takes place in achalasia has never been studied.

Esophageal emptying in the supine position (in the absence of gravity) should follow physical principles of pressure gradients across the esophago-gastric junction (EGJ). The goals of our studies were two folds, first; we used the technique of combined multiple intra-luminal impedance (MII) (to determine flow across the EGJ) and high resolution manometry (HRM) (to determine pressure gradients) to assess the mechanism by which esophageal emptying occurs in achalasia esophagus. Second, we recorded pressure (using HRM) and high frequency intraluminal ultrasound (HFIUS) images to determine the mechanism of esophageal pressure increase. Our studies identify a unique longitudinal muscle contraction pattern, which is responsible for intermittent emptying in achalasia esophagus.

\section{Materials \& Methods}

The Institutional Review Board of University of California San Diego approved the protocol for the studies and all participants signed an informed consent prior to their participation in the study.

\section{Simultaneous High Resolution Manometry (HRM), Multiple-intraluminal Impedance (MII) \& High Frequency Intraluminal Ultrasound (HFIUS) Imaging}

These studies were performed in 6 healthy asymptomatic subjects and 13 patients with achalasia of the esophagus. A combined HRM/MII catheter alone (4.2 mm diameter, Sierra Scientific Instrument, Los Angeles, CA) was used for these studies. The HRM/MII catheter was equipped with 36 pressure transducers spaced $1 \mathrm{~cm}$ apart and 18 impedance electrodes located $2 \mathrm{~cm}$ apart on the same catheter. The goal of the studies in normal subjects was to characterize flow patterns across the esophagogastric junction (EGJ) in response to swallows. Patients with achalasia esophagus, on the other hand, were studied using a catheter assembly consisting of combined HRM/MII catheter and a 6F (2 mm diameter) HFIUS catheter (From 
Boston Scientific Instruments, Boston, MA). The two catheters were taped together in such a fashion that the US transducer was located either just below the tip of the HRM/MII catheter, i.e., $5 \mathrm{~cm}$ below the last pressure transducer. In some recording, the US transducer was positioned between the $8^{\text {th }}$ and $9^{\text {th }}$ pressure transducer from the distal end of the HRM/MII catheter to record US images and pressures at the same level. When US transducer was located below the HRM catheter it was possible to image the entire circumference of the esophagus without HRM/MII catheter blocking the view of esophagus. On the other hand, when US transducer was located between $8^{\text {th }}$ and $9^{\text {th }}$ pressure transducer it was possible to record US images, esophagus, EGJ and stomach pressures and MII at the same time. However, approximately $20 \%$ of the circumference of the esophagus was missing in these US images due to shadowing of the US image by the HRM/MII catheter. In the first catheter configuration, 8 swallows were performed with the HRM catheter placed in such a fashion that 2 or 3 pressure transducers were located in the stomach. Catheter was then pulled back until the US transducer was located $2 \mathrm{~cm}$ above the LES and additional 8 swallows were performed. Finally, US transducer was relocated to $10 \mathrm{~cm}$ above the LES and 8 more wet swallows were recorded. In the second catheter configuration, catheter assembly was positioned such that the US transducer was located first at $2 \mathrm{~cm}$ and then at $10 \mathrm{~cm}$ above the LES, and at each location 8 swallows were performed. All swallows were performed using $5 \mathrm{ml}$ half normal saline to allow MII recordings of the esophagus.

\section{Data Analysis}

\section{High Resolution Manometry Record in Achalasia Patients - Retrospective Study}

Clinical manometry studies performed at UCSD's GI function laboratory between January and December 2008 with the diagnosis of achalasia esophagus were selected for analysis. All manometry recordings were performed using HRM system (Sierra Scientific Instruments, Los Angles, CA.) for evaluation of dysphagia/chest pain. HRM recordings were analyzed to determine 3 achalasia patterns, based on a recent HRM classification proposed by Pandolfino et $\mathrm{al}^{4}$. Briefly, the HRM criteria for diagnosing achalasia are absent peristalsis in the esophagus body and absent or incomplete EGJ relaxation. The magnitude of esophageal pressure increase in response to swallows differentiates 3 achalasia subtypes, in type 1, it was less than $30 \mathrm{mmHg}$ in type 2, at least 2 test swallows were associated with "panesophageal pressurization to greater than $30 \mathrm{mmHg}$ ". Panesophageal pressurization was defined when it extended from the UES to the LES, and in pattern 3 esophageal contractions were spastic (amplitude greater than 100 $\mathrm{mmHg}$ ). The HRM records were scored for pressure gradients between the esophagus and the EGJ.

Studies in Normal Subjects-HRM/MII records were analyzed to determine the relationship between pressure gradients between esophagus ( $2 \mathrm{~cm}$ above the EGJ) and the EGJ along with the impedance characteristics of flow across the EGJ. Two methods were used to determine flow across the EGJ by MII; 1) MII color plots superimposed on the HRM (commercial software, Sierra Scientific Instruments) and 2) a custom made algorithm to display impedance values from adjacent electrodes just above (proximal) and below (distal) the EGJ. In MII color plots, upper and lower filter impedance settings were arbitrarily selected to display what is perceived to be the appropriate impedance pattern. On the other hand, in our custom made algorithm, flow across the EGJ was defined when 2 impedance values fell below $2 \mathrm{k} \Omega$ (irrespective of their baseline value) and they became equal to each other. The $2 \mathrm{k} \Omega$ criteria was based on the in-vitro testing where we determined impedance values by placing the HRM catheter (4.2 mm diameter) in syringe barrels of 3, 5, 10 and $60 \mathrm{ml}$, filled with half normal saline. There was a decrease in the impedance with increase in syringe diameter, the impedance values with $3 \mathrm{ml}$ syringe (diameter $8 \mathrm{~mm}$ ) and $60 \mathrm{ml}$ syringe (diameter $26 \mathrm{~mm}$ ) were 1.931 .01 $\mathrm{k} \Omega$ respectively. We reasoned that reduction in impedance value to $2 \mathrm{k} \Omega$ represents minimal 
opening of the EGJ. The equality of impedance criteria was based on the rationale that if the EGJ were to open it should result in similar impedance values across the EGJ (figure 1 A \& B).

\section{Simultaneous HRM/MII and HFIUS Studies in Achalasia Patients}

The goal of these studies was to determine the longitudinal muscle contraction and esophageal lumen correlates of type 1,2 and 3 achalasia motor patterns.

HFIUS Image Analysis-The captured tomographic (B- mode) US images were analyzed to determine luminal cross sectional area (CSA) and muscle CSA using custom developed program developed in our laboratory ${ }^{10}$. Briefly, the program consists of converting B- mode images into $16 \mathrm{M}$-mode images; each M- mode image consists of a slice of B-mode images in planes $22.5^{\circ}$ apart, over time. In each M-mode image, the radial distance between the center of the image (US catheter location) and the inner luminal edge and outer esophageal wall was determined. Area of the triangular region encompassed by two adjacent radial lines was calculated (area $=0.5 * R 1 * R 2 * \sin \alpha$ - where $\mathrm{R} 1$ and $\mathrm{R} 2$ are two adjacent radius and $\alpha=$ $22.5^{\circ}$ (angle between the two radial lines). Total lumen CSA and muscle plus lumen CSA were obtained from the sum of sixteen areas. Muscle CSA was the difference between muscle plus mucosa and lumen CSAs.

Statistical Analysis-Data are shown as median values as indicated in the figure legends and elsewhere in the text. Statistical analysis was performed using non-parametric, Wilcoxon matched-pairs signed ranks test for all comparisons.

\section{RESULTS}

\section{Esophageal Motor Patterns in Achalasia Esophagus}

HRM records were reviewed from 32 patients (retrospective analysis) with a diagnosis of achalasia esophagus. Number of patients belonging to achalasia types 1, 2 and 3 were 3, 24 and 5 respectively. Figure 2, 3, $4 \& 5$ show representative HRM records from 3 achalasia subtypes. In type 2 achalasia patients, who represented majority of patient, swallows induced normal appearing pharyngeal contraction, upper esophageal sphincter relaxation and peristalsis in the most proximal, i.e., $3-5 \mathrm{~cm}$ length of the esophagus, following which there was cessation of esophageal activity. In some subjects, however, there was no peristalsis present even in the proximal esophagus. A few second later, a unique motor pattern, what we refer to as panesophageal pressurization motor pattern (PEPMP) emerged. PEPMP involved the UES, the esophagus and the LES and consisted of UES and LES contraction along with simultaneous pressure increase (panesophageal pressurization) throughout the length of the esophagus. The PEPMP lasted for a mean duration of $9.1 \pm 0.8 \mathrm{sec}$ after swallows (time when esophageal pressure was $>20 \mathrm{mmHg}$ ). Esophageal pressure decreased with inspiration and increased with expiration during PEPMP. The UES pressure as well as its length increased and UES was pulled in the aboral direction (figures 3, 4 and 7). On the other hand, LES ascended and LES pressure increased during PEPMP (figure 3).

In group 3 patients, swallows resulted in increase in esophageal pressure that was simultaneous and of high amplitude (pressure range 100 - $300 \mathrm{mmHg}$ ) (figure 5). The EGJ showed partial relaxation followed by spastic contraction and UES show strong contraction during spastic esophageal contraction.

\section{Impedance Characteristics of Flow across the EGJ in Normal Subjects}

60 swallows were analyzed in 6 subjects. A decrease in impedance following swallow was seen as pink color superimposed on the HRM color plot. The wave of pink color traversed the 
esophagus in a peristaltic fashion, in advance of the peristaltic pressure wave. The flow across the EGJ, in a normal subject, was seen as an uninterrupted pink color bridge during swallowinduced EGJ relaxation (figure 1A, B \& C). When the upper and lower limits of filter setting of impedance were altered, the duration and color intensity of bridge changed significantly thus making the bridge of longer or shorter duration (figure 1B). Therefore, it was difficult to know the precise timing of flow across the EGJ based on the impedance color plot. On the other hand, fall in impedance values of electrode pairs above and below the EGJ to less than $2 \mathrm{k} \Omega$ and to the same level was observed for a consistent period during all swallows and provided a more objective assessment of the flow across the EGJ. The pressure gradient between the esophagus and EGJ was less than $3 \mathrm{mmHg}$ during all those times that met our criteria of EGJ flow. On the other hand, the pressure gradient was higher during the periods of no EGJ flow. For example, with each inspiration related increase in the EGJ pressure during the relaxation period a cessation of flow was noticed.

\section{Flow Across the Esophagogastric Junction in Patients with Achalasia Esophagus}

13 patients with achalasia esophagus were studied using simultaneous HRM/MII and HFIUS. Number of subjects belonging to types 1,2 and 3 achalasia motor pattern was 2, 7 and 4 respectively. In all achalasia subjects, bolus entered into the esophagus with each swallow but flow across the EGJ, as determined from our MII criteria, occurred only intermittently. In one of the patient with type 1 achalasia, there was no flow across the EGJ during the entire recording period; patient vomited during the study. In the other type 1 achalasia patient, the EGJ pressure was relatively low and PEPMP was noticed following swallow that resulted in esophageal pressures of 20-30 mm Hg. Flow across the EGJ was noticed with all swallows and it occurred when esophageal pressure during PEPMP equaled the EGJ pressure.

In type 2 achalasia patients, flow across the EGJ occurred only during swallow induced PEPMP and at a time when the EGJ pressure was relatively low. Figure 3 show the esophageal and EGJ pressure at time of flow across the EGJ. Only $36 \%$ of 56 swallows in 7 subjects (1-7swallows/subject) were followed by a flow across the EGJ and all of these occurred during periods of panesophagal pressurization. Swallows that resulted in flow across the EGJ revealed lower difference in the pressure gradient between esophagus and EGJ compared to those that did not show flow (figure 6A). However, there were large numbers of instances that showed flow across the EGJ even when the esophageal pressure was still lower than the peak EGJ pressure.

In type 3 achalasia patients, bolus transport along the esophagus occurred in a peristaltic manner (ahead of the simultaneous pressure wave) and flow across the EGJ occurred with $72 \%$ of 32 swallows recorded in 4 patients (range 3-8 swallows per subject). Flow across the EGJ occurred during swallow-induced incomplete EGJ relaxation during the initial part of the esophageal pressurization.

\section{Esophageal Motor Patterns by HRM and HFIUS Images}

Relationship between pressure and ultrasound image finding in patients with achalasia are quite different in 3 subtypes (figures 2-5 \& 7). One patient with type 1 achalasia, with no increase in esophageal pressure, showed slight esophageal distension following swallows and no change in the muscle CSA (a marker of longitudinal muscle contraction). The second patient with type 1 achalasia revealed PEPMP that was similar to type 2 achalasia albeit the esophageal pressures were $<30 \mathrm{mmHg}$. US image analysis in type 2 achalasia revealed a decrease in the esophageal lumen and an increase in the muscle CSA at $2 \mathrm{~cm}$ above LES during PEPMP (figure 3 ). The changes in esophageal pressure during PEPMP paralleled those in muscle CSA. At no point during PEPMP there was complete obliteration of esophageal lumen indicating that the esophageal pressure during PEPMP was cavity pressure rather than the contact pressures. 
Changes in the muscle CSA during PEPMP were larger at 2 compared with $10 \mathrm{~cm}$ above the EGJ (figure 6B).

In type 3 achalasia, baseline esophageal muscle was thicker as compared to type 1 and 2 patients and lumen was not distended (figure 7). Majority of swallows resulted in an increase followed by decrease and complete obliteration of the esophageal lumen. Muscle CSA decreased initially but then increased with a slow return to baseline value. There was poor coordination between change in pressure and muscle CSA.

\section{DISCUSSION}

In summary, our data show the following; 1 ) we identified a novel algorithm which we propose can be used to determine flow across the EGJ using MII technique. 2) The 3 achalasia subtypes identified by HRM show distinct esophageal emptying and longitudinal muscle contraction patterns in response to swallow. 3) We describe PEPMP, which is characterized by simultaneous pressure increase throughout the length of the esophagus (panesophageal pressurization) that is associated with esophageal emptying in the predominantly seen achalasia subtype i.e., type 2 . We identified a unique longitudinal muscle contraction of the distal esophagus in association with panesophageal pressurization, which we propose is the major mechanism of esophageal emptying in achalasia.

Aperistalsis or complete lack of peristalsis is the hallmark of achalasic esophagus. Complete absence of pressure waves following swallows, as seen in one of our achalasic is relatively less common; more frequent are the low amplitude simultaneous pressure waves along the entire length of the esophagus. The accepted definition of simultaneous pressure wave is based on the onset and not the peak or the end of pressure wave11. Simultaneous pressure waves in type 2 achalasia shows that the onset, peak as well as the end of pressure waves are all simultaneous and these pressure waves actually represent cavity pressure waves rather than the true contractions i.e., contact pressures. On the other hand, swallow-induced pressure waves in type 3 achalasia patients are different in that they are simultaneous in onset but at times the peak and end may be peristaltic. The PEPMP seen in type 1 and 2 achalasia patients is unique in that it actually follows the cessation of peristalsis in proximal esophagus and involves contraction of the upper esophageal sphincter, LES and simultaneous pressure waves. The upper esophageal sphincter gets pulled downwards and the LES gets pulled upwards during PEPMP, possibly related to the longitudinal muscle contraction. Ultrasound imaging confirms that the increase in esophageal pressure in PEPMP is indeed a cavity and not the occlusion pressure because occlusion or complete collapse of the lumen is not noticed. Ultrasound images also show that there is marked increase in muscle CSA, a marker of longitudinal muscle contraction 12,13 during PEPMP. There is a strong correlation between the amplitude of longitudinal muscle contraction with increase and decrease in the esophageal pressure increase during PEPMP in a given subject. We propose that the longitudinal muscle contraction is actually the cause of pressure increase in the esophagus and the mechanism is as follows, 1) longitudinal muscle contraction makes the wall of esophagus rigid (decrease esophageal compliance) and 2) longitudinal muscle contraction decreases esophageal length because the LES gets pulled in oral direction. Both of the above factors decrease the esophageal volume. Since achalasia esophagus is sealed at the two ends by a closed UES and a non-relaxing LES, decrease in the cavity volume results in an increase in esophageal pressure (Boyle's law of physics).

Longitudinal muscle contraction patterns, as recorded by ultrasound images in 3 subtypes of achalasia are quite different. In type 1 achalasia patient with no increase in esophageal pressure following swallows there is no longitudinal muscle contraction. The type 2 achalasia with PEPMP as their major motor pattern show that the longitudinal muscle contraction is preserved 
even though the pattern of contraction is different from normal subjects where circular and longitudinal muscle contract synchronously during peristalsis ${ }^{14}$. During PEPMP there is no occlusion of esophageal lumen suggesting disordered circular muscle contraction. However, we can't be sure if the circular muscle contraction is completely absent or it is reduced in force, which prevents complete lumen occlusion. We observed that the amplitude of longitudinal muscle contraction is stronger at the $2 \mathrm{~cm}$ as compared to $10 \mathrm{~cm}$ above the LES, a pattern similar to what we recently described during transient LES relaxation in normal subjects ${ }^{15}$. A mechanical stretch on the LES caused by longitudinal muscle contraction of the esophagus induces a neurologically mediated LES relaxation ${ }^{16,17}$. It is tempting to speculate that the strong and repeated longitudinal muscle contraction of the esophagus in achalasia esophagus are efforts to induce LES relaxations, however these efforts fail because of lack of nitric oxide containing motor neuron in the $\mathrm{LES}^{2}, 3$. In type 3 achalasia patients there appears to be reduced and discoordinated longitudinal muscle contraction along with somewhat preserved circular muscle contraction. Discoordination between circular and longitudinal muscle contraction of the esophagus is also seen in patients with nutcracker esophagus ${ }^{18,19}$. Simultaneous onset of pressure waves in type 3 achalasia patients is because the onset of esophageal pressure wave reflects cavity pressure and the later part of the pressure waves is the contact pressure related to circular muscle contraction. Ultrasound images show presence of lumen during early part of the pressure wave and complete lumen obliteration during the later part of pressure waves. We observed similar type of manometric pressure waves in the esophagus in an experimental model of obstructed esophagus ${ }^{20}$.

The MII technique has been used to record gastro-esophageal reflux extensively because of its ability to identify liquid and air reflux, irrespective of the $\mathrm{pH}$ of reflux contents $21^{-23}$. MII has also been used to study transit of bolus along the length of the esophagus. Several commercial companies (Sierra Scientific Instruments, Sand Hill Scientific and MMS) have developed catheters with 32-36 solid-state pressure sensors and up to 18 impedance electrodes located on the same catheter to record HRM and MII simultaneously. The latter provides unique opportunity to assess the relationship between pressure gradients and bolus movement along the esophagus and across the EGJ. The MII recordings can be displayed as color plots or waveforms superimposed on the HRM plots. Using our criteria, which are dependent on the absolute impedance values and not any filter settings, we observed that flow across the EGJ occurs at times when the pressure gradient between the esophagus and the EGJ was less than $3 \mathrm{mmHg}$ in normal subjects. Furthermore, this pressure gradient was lower during the times of flow as compared to no flow. Of the 60 swallows that we analyzed in normal subjects, flow across the EGJ was noticed during all of the swallows.

To the best of our knowledge, the mechanism by which esophageal emptying occurs in achalasia esophagus has never been studied. It is generally assumed that the gravity and postures designed to increase intra-thoracic and hence esophageal pressure must play important roles. We observed that in the supine position, when gravity is eliminated, the mechanism of esophageal emptying is quite different in 3 types of achalasia. In one type 1 achalasia patient where there was no increase in esophageal pressure following swallows, no emptying into the stomach took place during the study period. We believe that in such a patient gravity and posture are likely to be the mechanisms of esophageal emptying. On the other hand, in type 3 achalasia patients esophageal emptying of liquids occurred with most of the swallows. In type 2 achalasia patients, who represent the majority of achalasia patients, esophageal emptying is related to panesophageal pressurization. Furthermore, longitudinal muscle contraction of the distal esophagus is most likely the major factor that results in an increase in esophageal pressure during PEPMP. It is interesting that Tutian et $\mathrm{al}^{22}$ and Pandolfino et $\mathrm{al}^{4}$ also suspected longitudinal muscle contraction of the esophagus, based on the LES lift on HRM, as the cause of panesophageal pressurization,. 
There are two limitations of our study, 1) we only studied subjects in the supine - position, the reason for which was that we wanted to exclude the possible role of gravity and weight of esophageal contents in esophageal emptying and 2) we did not study esophageal emptying of solid foods. Withstanding above limitation, our data provide strong support for achalasia classification proposed by Pandolfino et $\mathrm{al}^{4}$. Besides distinct HRM motor patterns and differences in response to therapy, 3 achalasia subtypes have different patterns of longitudinal muscle contraction following swallows and different patterns of esophageal emptying. We are not sure if these 3 different types of achalasia represent different phenotypes during progression of the disease caused by the same process or if they represent 3 different disease states. Our own bias is that they represent the former rather than the later. We speculate that the motor abnormalities in the body of the esophagus in achalasia are secondary to dysfunctional LES (poor relaxing or non-compliant). We propose that type 3 and type 1 achalasia esophagus represent compensated and de-compensated esophagus respectively, in response to outflow obstruction caused by the dysfunctional LES. On the other hand, PEPMP in type 2 achalasia represents a novel esophageal motor response where the normal peristaltic pattern of esophagus is altered to a unique pattern that involves longitudinal muscle contraction of the distal esophagus. The latter increases esophageal pressures to create a favorable pressure gradient for emptying of the esophagus.

\section{Acknowledgments}

Authors are indebted to Debbie Orban for technical assistance

Supported by: NIH Grant: RO1-DK060733

\section{Abbreviations}

$\begin{array}{ll}\text { MII } & \text { Multiple Intraluminal Impedance } \\ \text { HFIUS } & \text { High Frequency Intraluminal Ultrasound } \\ \text { HRM } & \text { High Resolution Manometery }\end{array}$

\section{References}

1. Goldblum JR, Rice TW, Richter JE. Histopathologic features in esophagomyotomy specimens from patients with achalasia. Gastroenterology 1996;111:648-54. [PubMed: 8780569]

2. Hirano I, Tatum RP, Shi G, Sang Q, Joehl RJ, Kahrilas PJ. Manometric heterogeneity in patients with idiopathic achalasia. Gastroenterology 2001;120:789-98. [PubMed: 11231931]

3. Mearin F, Mourelle M, Guarner F, et al. Patients with achalasia lack nitric oxide synthase in the gastrooesophageal junction. Eur J Clin Invest 1993;23:724-8. [PubMed: 7508398]

4. Pandolfino JE, Kwiatek MA, Nealis T, Bulsiewicz W, Post J, Kahrilas PJ. Achalasia: a new clinically relevant classification by high-resolution manometry. Gastroenterology 2008;135:1526-33. [PubMed: 18722376]

5. Nylander DL, Aithal GP, Tanner AR, Dellipiani AW, Dwarakanath DA. Chest pain in achalasia is an age-dependent phenomenon. Gastroenterology 1999;117:1259. [PubMed: 10610338]

6. Eckardt VF, Stauf B, Bernhard G. Chest pain in achalasia: patient characteristics and clinical course. Gastroenterology 1999;116:1300-4. [PubMed: 10348812]

7. Spechler SJ, Souza RF, Rosenberg SJ, Ruben RA, Goyal RK. Heartburn in patients with achalasia. Gut 1995;37:305-8. [PubMed: 7590421]

8. Holloway RH, Krosin G, Lange RC, Baue AE, McCallum RW. Radionuclide esophageal emptying of a solid meal to quantitate results of therapy in achalasia. Gastroenterology 1983;84:771-6. [PubMed: 6825989] 
9. Massey BT, Dodds WJ, Hogan WJ, Brasseur JG, Helm JF. Abnormal esophageal motility. An analysis of concurrent radiographic and manometric findings. Gastroenterology 1991;101:344-54. [PubMed: 2065909]

10. Abrahao LJ, Babaei A, Bhargava V, Ho A, Mittal RK. Swallow Induces a Peristaltic Wave of Inhibition That Marches In Front of the Peristaltic Wave of Contraction Along the Length of the Esophagus in Normal Subjects. Gastroenterology 2008;134(Sup 1):A560.

11. Richter JE, Castell DO. Diffuse esophageal spasm: a reappraisal. Ann Intern Med 1984;100:242-5. [PubMed: 6691670]

12. Nicosia MA, Brasseur JG, Liu JB, Miller LS. Local longitudinal muscle shortening of the human esophagus from high-frequency ultrasonography. Am J Physiol Gastrointest Liver Physiol 2001;281:G1022-33. [PubMed: 11557523]

13. Mittal RK, Liu J, Puckett JL, et al. Sensory and motor function of the esophagus: lessons from ultrasound imaging. Gastroenterology 2005;128:487-97. [PubMed: 15685559]

14. Mittal RK, Padda B, Bhalla V, Bhargava V, Liu J. Synchrony between circular and longitudinal muscle contractions during peristalsis in normal subjects. Am J Physiol Gastrointest Liver Physiol 2006;290:G431-8. [PubMed: 16210472]

15. Babaei A, Bhargava V, Korsapati H, Zheng WH, Mittal RK. A unique longitudinal muscle contraction pattern associated with transient lower esophageal sphincter relaxation. Gastroenterology 2008;134:1322-31. [PubMed: 18384786]

16. Dogan I, Bhargava V, Liu J, Mittal RK. Axial stretch: A novel mechanism of the lower esophageal sphincter relaxation. Am J Physiol Gastrointest Liver Physiol 2007;292:G329-34. [PubMed: 17023549]

17. Jiang Y, Bhargava V, Mittal RK. Mechanism of stretch-activated excitatory and inhibitory responses in the lower esophageal sphincter. Am J Physiol Gastrointest Liver Physiol 2009;297:G397-405. [PubMed: 19520741]

18. Korsapati H, Bhargava V, Mittal RK. Reversal of asynchrony between circular and longitudinal muscle contraction in nutcracker esophagus by atropine. Gastroenterology 2008;135:796-802. [PubMed: 18675815]

19. Jung HY, Puckett JL, Bhalla V, et al. Asynchrony between the circular and the longitudinal muscle contraction in patients with nutcracker esophagus. Gastroenterology 2005;128:1179-86. [PubMed: 15887102]

20. Mittal RK, Ren J, McCallum RW, Shaffer HA Jr. Sluss J. Modulation of feline esophageal contractions by bolus volume and outflow obstruction. Am J Physiol 1990;258:G208-15. [PubMed: 2305886]

21. Kahrilas PJ, Sifrim D. High-resolution manometry and impedance-pH/manometry: valuable tools in clinical and investigational esophagology. Gastroenterology 2008;135:756-69. [PubMed: 18639550]

22. Tutuian R, Castell DO. Combined multichannel intraluminal impedance and manometry clarifies esophageal function abnormalities: study in 350 patients. Am J Gastroenterol 2004;99:1011-9. [PubMed: 15180718]

23. Bredenoord AJ, Tutuian R, Smout AJ, Castell DO. Technology review: Esophageal impedance monitoring. Am J Gastroenterol 2007;102:187-94. [PubMed: 17100961] 

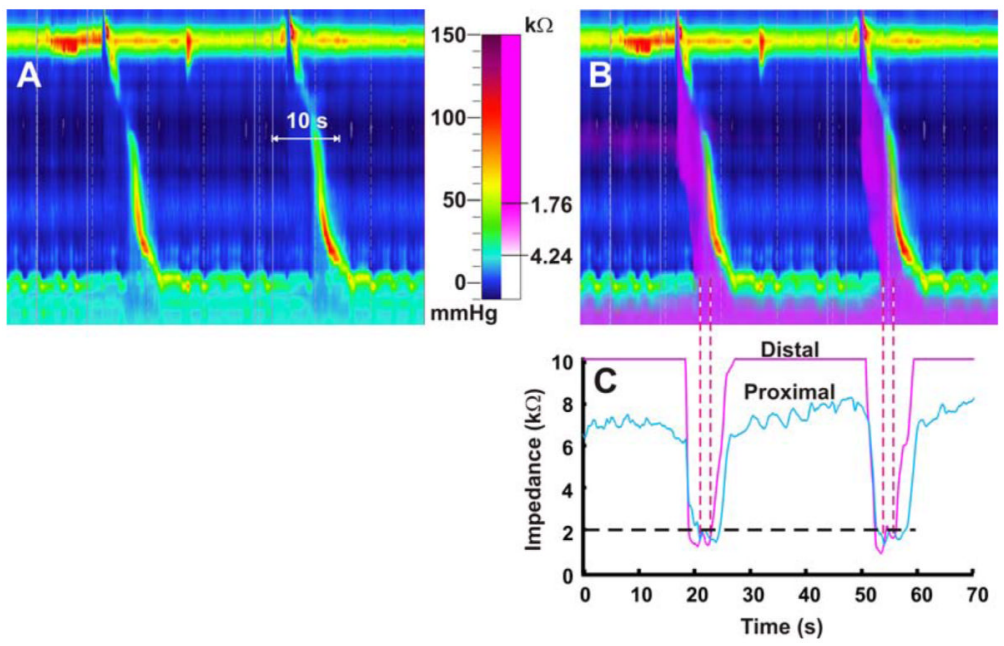

Figure 1.

Panels A \& B show simultaneous high-resolution esophageal manometry and high-resolution esophageal manometry with impedance in a normal subject: pink color, in panel B, represents changes in impedance as a marker of bolus movement along the length of esophagus. Note the temporal correlation between impedance and pressure wave in the esophagus and the EGJ. Flow across the EGJ is seen as a pink bridge across the EGJ. The width of bridge is dependent on the impedance filter settings (A \& B). Panel C graph represents absolute impedance values from pair of electrodes located just above and below the EGJ. Note, the fall in impedance values to below $2 \mathrm{k} \Omega$ and equal to each other, is a marker of flow across the EGJ (see methods and result section). Horizontal dashed line represents $2 \mathrm{k} \Omega$ value in panel $\mathrm{C}$. 

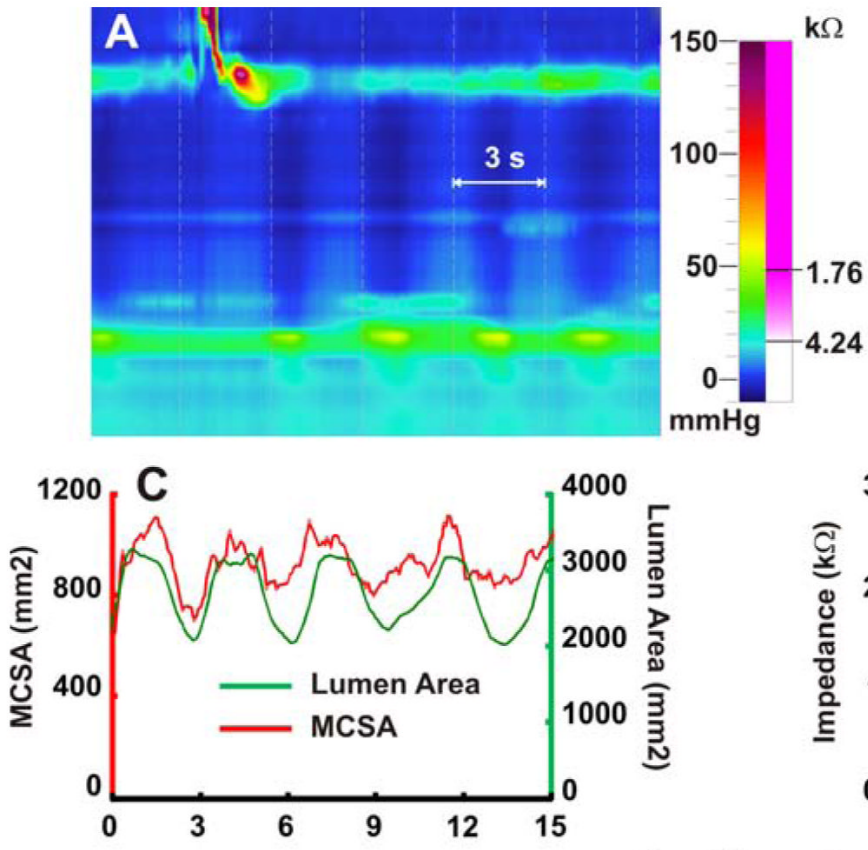

B

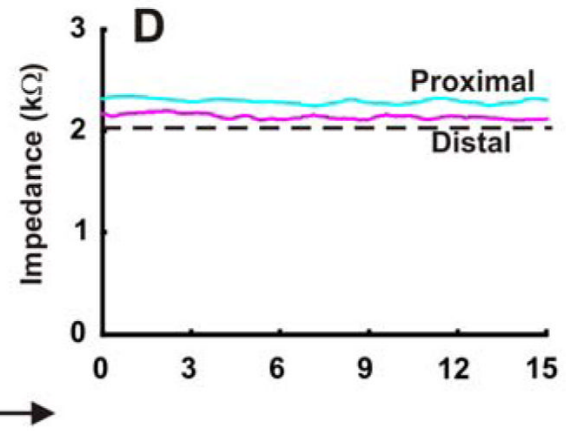

Figure 2.

Simultaneous high resolution manometry, impedance and ultrasound image recorded changes in esophageal lumen and muscle cross sectional area (MCSA) in a patient with type 1 achalasia: Panel A - HRM alone, panel B - HRM and impedance, panel C - changes in muscle cross sectional area and lumen (derived from US images) and panel D - impedance recording from the pair of electrodes above and below the EGJ. Following swallow, there is no increase in esophageal pressure and EGJ relaxation (type 1 achalasia). Impedance recording shows no flow across the EGJ and US image derived data show no change in luminal and muscle CSA. Rhythmical changes in muscle and luminal CSA reflect respiration-induced fluctuations. Horizontal dashed line represents $2 \mathrm{k} \Omega$ value in panel $\mathrm{D}$. 

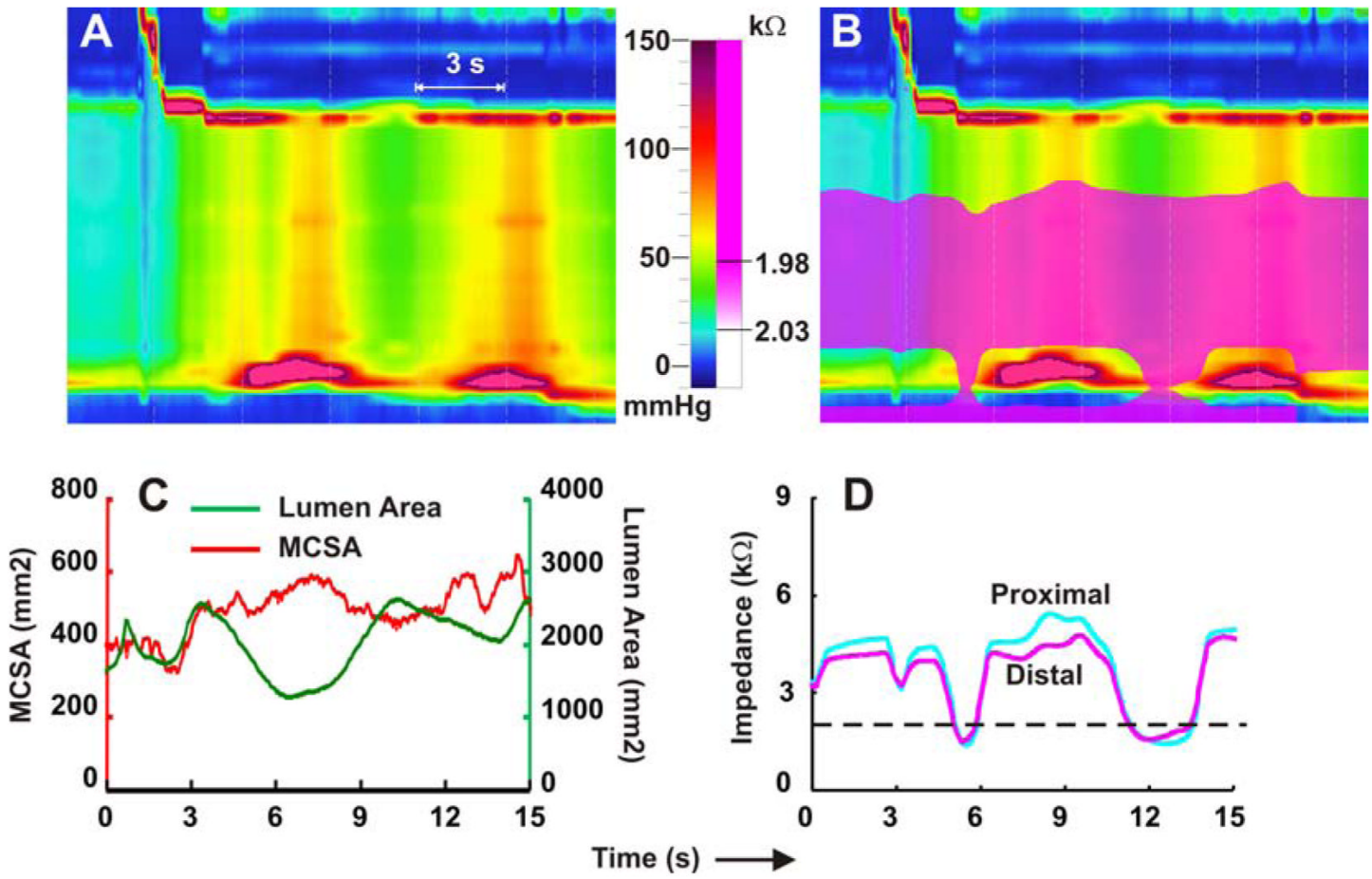

Figure 3.

Simultaneous high resolution manometry, impedance and ultrasound image recorded changes in esophageal lumen and muscle cross sectional area (MCSA) in a patient with type 2 achalasia: panel A - HRM alone, panel B - HRM and impedance, panel C - changes in muscle cross sectional area and lumen (derived from US images) and panel D - impedance recording from the pair of electrodes above and below the EGJ. Following swallow there is simultaneous pressure wave throughout the length of the esophagus (common cavity wave- panesophageal pressurization). EGJ record shows minimal relaxation to contraction following swallow. Impedance recording shows intermittent flow (seen twice in the record) seen as the development of pink bridge across the EGJ and fall in impedance values to below $2 \mathrm{k} \Omega$ and equal to each other from the pair of electrodes above and below the EGJ. US image derived data show decrease in luminal CSA and increase in muscle CSA during the period of common cavity pressure wave (panesophageal pressurization). Increase in muscle CSA suggests contraction of the longitudinal muscle of the esophagus. Horizontal dashed line represents 2 $\mathrm{k} \Omega$ value in panel $\mathrm{D}$. 

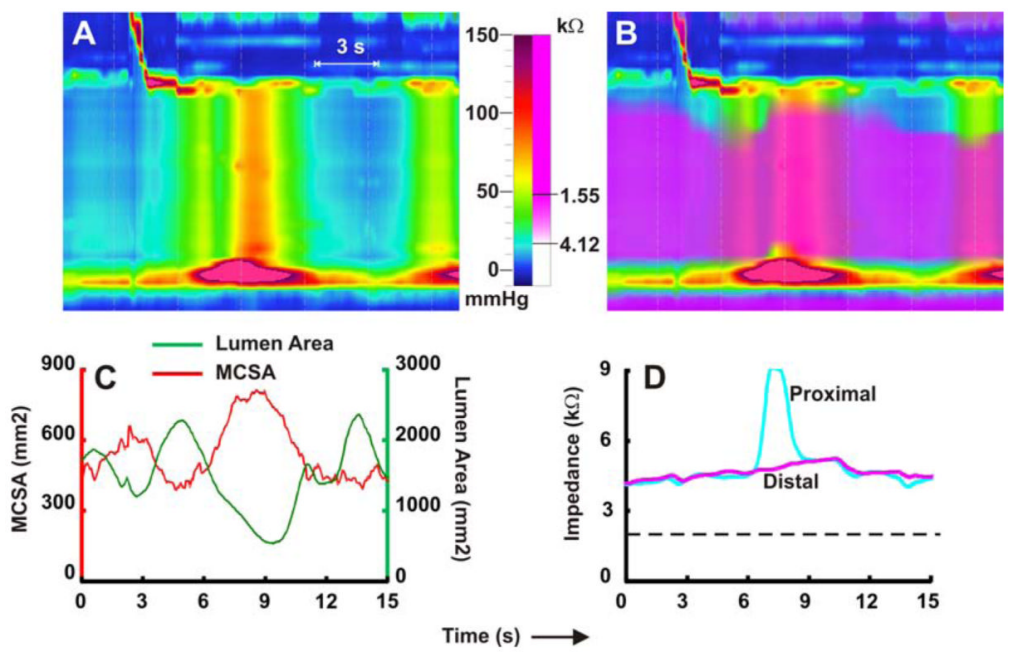

Figure 4.

Simultaneous high resolution manometry, impedance and ultrasound image recorded changes in esophageal lumen and muscle cross sectional area (MCSA) in a patient with type 2 achalasia: panel A - HRM alone, panel B - HRM and impedance, panel C - changes in muscle cross sectional area and lumen (derived from US images) and panel D - impedance recording from a pair of electrodes above and below the EGJ. Following swallow there is simultaneous pressure wave throughout the length of the esophagus (common cavity wave- panesophageal pressurization). EGJ record shows minimal relaxation to contraction following swallow. Impedance recording show no flow across the EGJ, seen as an absence of pink bridge across the EGJ and absence of fall in impedance values to below $2 \mathrm{k} \Omega$ by the pair of electrodes above and below the EGJ. US image derived data show decrease in luminal CSA and increase in muscle CSA during the period of common cavity pressure wave (panesophageal pressurization). Increase in muscle CSA suggests contraction of the longitudinal muscle of the esophagus. Horizontal dashed line represents $2 \mathrm{k} \Omega$ value in panel D. 

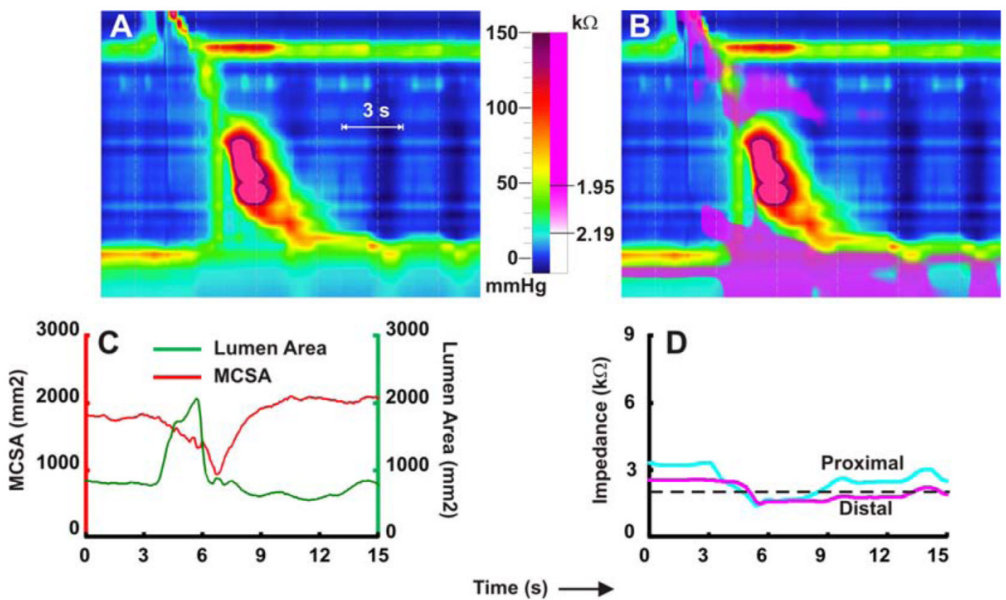

Figure 5.

Simultaneous high resolution manometry, impedance and ultrasound image recorded changes in esophageal lumen and muscle CSA in a patient with type 3 achalasia: panel A - HRM alone, panel B - HRM and impedance, panel C - changes in muscle cross sectional area and lumen (derived from US images) and panel D - impedance recording from a pair of electrodes above and below the EGJ. Following swallow, the onset of pressure wave is simultaneous but the end of wave is peristaltic. EGJ record shows incomplete relaxation following swallow. Impedance recording shows flow seen as the development of pink bridge across the EGJ and fall in impedance values to below $2 \mathrm{k} \Omega$ and equal to each other from the pair of electrodes above and below the EGJ. US image derived data show complete obliteration of luminal CSA suggesting normal movement of bolus. Changes in muscle CSA suggests an initial fall or relaxation of the longitudinal muscle followed by as small increase that does not return to baseline value promptly. The latter suggests discoordination of longitudinal and circular muscle contraction. Horizontal dashed line represents $2 \mathrm{k} \Omega$ value in panel D. 


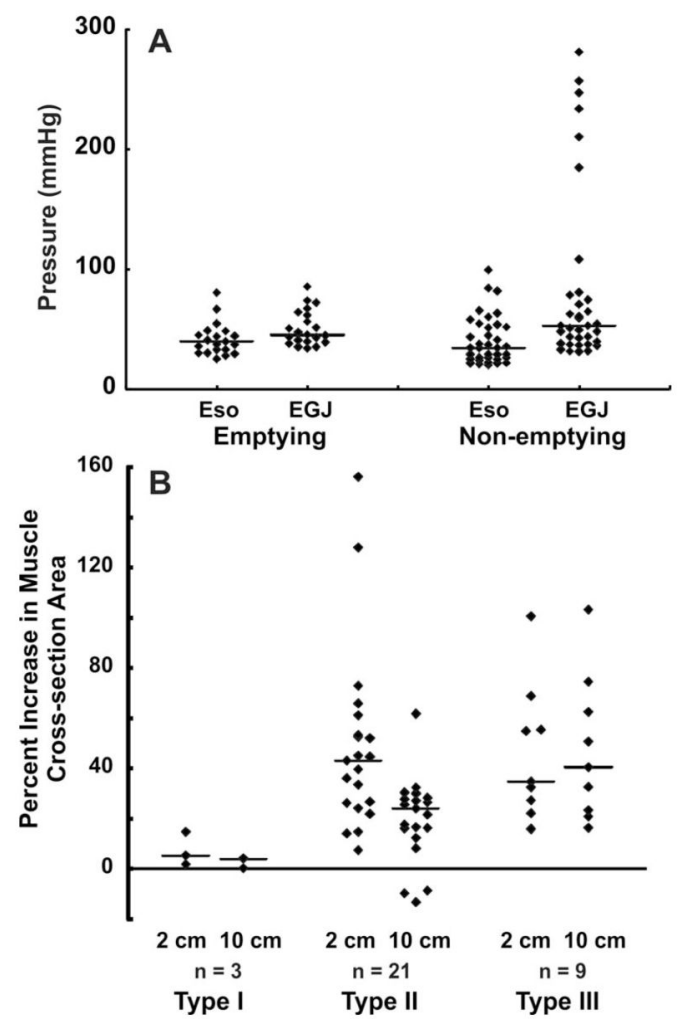

Figure 6.

Panel A- Esophagus and esophagogastric junction (EGJ) pressure during swallows associated with and without esophageal emptying in patients with type 2 achalasia esophagus. Esophageal emptying was determined from the impedance recording criteria described in the method section. Note, that the esophageal pressure was not different between the two groups but the EGJ pressure was lower in the group associated with emptying compared to that with no emptying. Horizontal lines represent median values. Panel B- Longitudinal muscle contraction pattern in patients with type 1,2 and 3 achalasia, at 2 and $10 \mathrm{~cm}$ levels above EGJ. See methods section for the details of criteria for 3 achalasia subtypes. Note, that swallows are not followed by any increase in muscle CSA (longitudinal muscle contraction) in achalasia type 1 . On the other hand, type 2 achalasia patients demonstrate a strong significant longitudinal muscle contraction that is stronger at the $2 \mathrm{~cm}$ level compared to $10 \mathrm{~cm}$ above the EGJ. Patients with type 3 achalasia show a smaller longitudinal muscle contraction, which is not different at 2 and $10 \mathrm{~cm}$ above the EGJ. Horizontal lines represent median values. 
$2 \mathrm{~cm}$
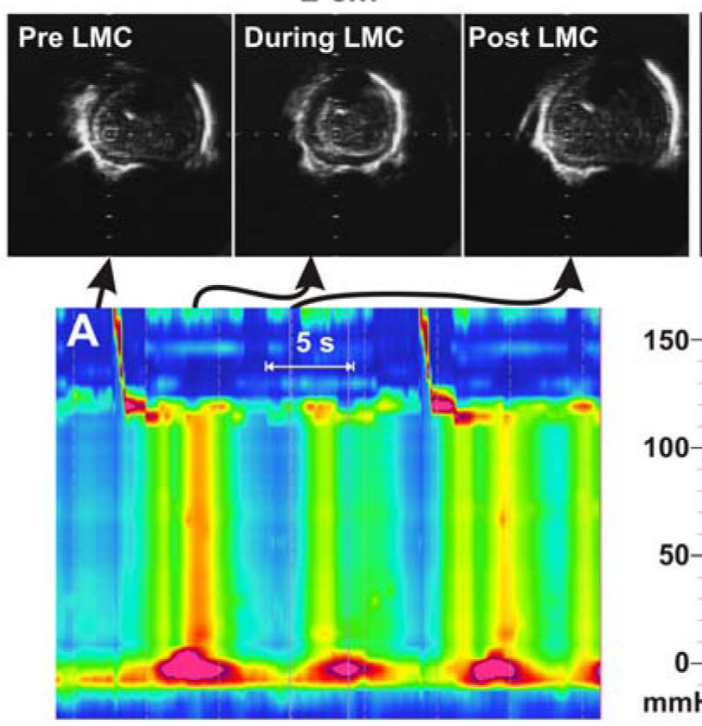

900

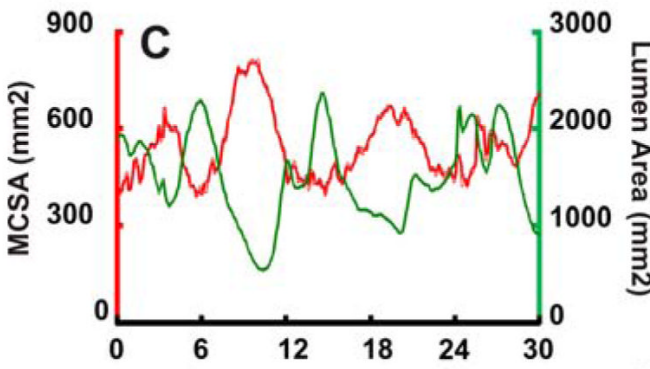

$10 \mathrm{~cm}$

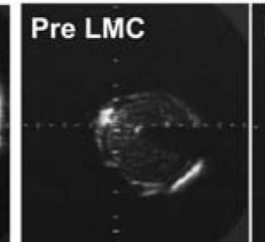

During LMC

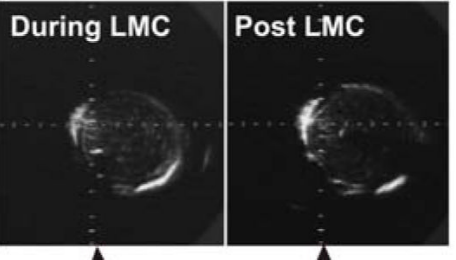

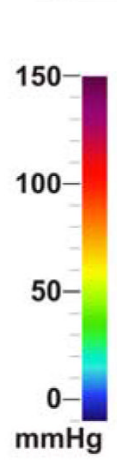
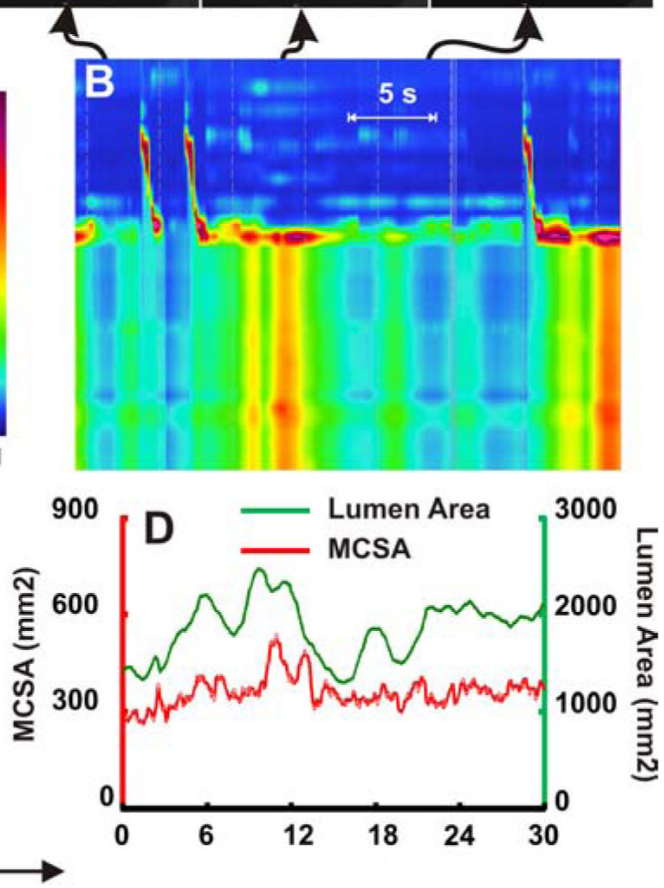

Figure 7.

Pattern of longitudinal muscle contraction in patients with type 2 achalasia: US images and high-resolution manometry (HRM) were recorded first with the US transducer located $2 \mathrm{~cm}$ above the EGJ and then at $10 \mathrm{~cm}$ above the EGJ. Top panel shows B-mode (tomographic) images, middle panels (A and B) show HRM pressure record and lower panels (C and D) show changes in luminal and muscle CSA derived from the US images. Swallow is followed by a simultaneous pressure (common cavity) wave along the length of the esophagus. B-mode US images at different time intervals during the simultaneous pressure wave shows increase in muscle thickness with the increase in pressure. Note that the increase in muscle thickness is greater at 2 compared to $10 \mathrm{~cm}$ above EGJ. Panel C shows data derived from the US images. Note in US images a greater increase in the muscle CSA at 2 compared to $10 \mathrm{~cm}$ above EGJ, which suggests a stronger contraction of the longitudinal muscle in distal compared to proximal esophagus. 